\title{
Crítica a la acrítica en Cantos de las guerras preventivas, de Fernando Contreras ${ }^{1}$
}

\section{Roy Alfaro Vargas ${ }^{2}$}

Universidad de Costa Rica

\section{RESUMEN}

Este artículo presenta un análisis de la novela Cantos de las guerras preventivas, de Fernando Contreras tratando de establecer los elementos posmodernos que funcionan a nivel textual, como medio para abordar el texto como antiutopía. Se estudia el papel del deseo insatisfecho en relación con la trama textual, con el fin de señalar las fallas que existen en relación con la crítica que el autor pretende dirigir contra las guerras preventivas.

\section{Abstract}

This article presents as analysis of Fernando Contreras' novel Cantos de las guerras preventivas, in an effort to establish the postmodern elements existing in the text, and to approach it within the anti-utopian genre. The role of unsatisfied desire is addressed with regard to the plot, in order to discuss the failures existing with regard to the author's criticism of preventive wars.

Palabras clave: literatura costarricense, narrativa costarricense contemporánea, posmodernidad, utopía.

Keywords: Costa Rican literature, contemporary Costa Rican narrative, post-modernity, utopia.

${ }^{1}$ Recibido: 2 de setiembre de 2008; aceptado: 20 de abril de 2009.

${ }^{2}$ Correo electrónico: royalfarov@gmail.com 


\section{Introducción}

En la novela de Fernando Contreras Castro, Cantos de las guerras preventivas $^{3}$, se plantea un tema actual: la política norteamericana en la administración de George W. Bush. Hay un intento de hacer crítica, pero desde nuestra perspectiva, su esfuerzo es insuficiente. Aquí emprendemos el análisis del texto Cantos de las guerras preventivas de Contreras Castro, partiendo de la siguiente tesis: esta obra se estructura como una antiutopía, en la cual el deseo insatisfecho funciona como elemento aglutinante del relato, como manifestación cultural posmoderna. Para ello, perseguimos estos objetivos: a. delimitar el contexto histórico-literario de la narrativa de Fernando Contreras; b. señalar las características de la posmodernidad; c. determinar las características de los conceptos de utopía y de antiutopía; d. establecer las características del texto analizado que permiten catalogarlo como una antiutopía; e. caracterizar el concepto de deseo; y f. establecer la relación existente entre el deseo insatisfecho y la posmodernidad, en Cantos de las guerras preventivas.

\section{La Promoción del 1980}

Álvaro Quesada ha ubicado a Contreras dentro de la promoción de $1980^{4}$, caracterizada por poner en duda las interpretaciones oficiales, dentro de esquemas narrativos que combinan, por ejemplo, el dato histórico con lo fantástico, incorporando mitos $\mathrm{y}$ leyendas marginales, por medio de anacronismos. Además, en esta generación se marca textual e ideológicamente, una desilusión sobre ideales como la democracia, el

${ }^{3}$ Fernando Contreras Castro, Cantos de las guerras preventivas (San José: Farben, 2006). En adelante, para esta obra se indicará el número de página en paréntesis al final de la cita.

4 Álvaro Quesada Soto, «La narrativa costarricense del último tercio de siglo», Letras XXXII (2000): 17-43. 
progreso y la verdad clásica con el empleo de la ironía, la parodia, las reversiones y el humor irreverente. Hay un incremento del sentimiento de enajenación del sujeto, dentro de un mundo que es representado de manera hostil, con tonos grotescos o absurdos, y que, a la vez, es incomprensible o sin sentido. Con respecto al lector, esta generación exige un lector activo en la interpretación de un relato que es absurdo, ambivalente y lleno de duda.

Los autores de esta promoción se insertan en un mundo que va desde el auge revolucionario de las décadas de 1960 y 1970, hasta el establecimiento del capitalismo globalizado, el neoliberalismo y el posmodernismo desesperanzado de finales del siglo $\mathrm{XX}^{5}$. En este contexto, la narrativa contreriana es una plasmación textual de la crítica del humanismo ${ }^{6}$; crítica que supone el abandonar el sujeto epistemológico, para crear un sujeto interpretante, no ya ligado a la episteme, sino a la doxa; lo cual es evidente en el tipo de lector activo que se pretende.

\section{Posmodernidad}

La posmodernidad puede definirse como el consumo de la pura mercantilización como proceso» ${ }^{7}$. Es decir, la posmodernidad es un fenómeno que va unido a la explosión del capitalismo ${ }^{8}$. El fenómeno posmoderno responde a la lógica de un capitalismo que abandona su fase productiva, entendida como la fase en la cual el capital está en función de producir bienes y servicios, y pasa a una fase financiera, en donde lo importante es lo bursátil.

Desde una perspectiva epistemológica, se da un desplazamiento desde el objeto al sujeto y desde la cosa al significado9; el

\footnotetext{
${ }^{5}$ Quesada Soto, 42-43.

${ }^{6}$ Óscar Gerardo Alvarado Vega, «La incidencia de lo posmoderno en la novela Los Peor, de Fernando Contreras», Káñina XXX, 2 (2006): 75-89.

${ }^{7}$ Fredric Jameson, Teoría de la posmodernidad (Madrid: Trotta, 1998) 10.

${ }^{8}$ Alvarado Vega, 79.

${ }^{9}$ Ernest Gellner, Posmodernismo, razón y religión (Barcelona: Paidós, 1994) 38.
} 
sujeto (o interpretante) toma el mundo y crea un significado (sens, Sinn) dentro de un juego de significantes, en donde «las cosas vienen a la existencia y la pierden al ser nombradas» ${ }^{10}$. Así, la verdad, entendida como la relación entre Ser y pensamiento, deviene en escisión, cuando se produce una esquizo-fragmentación ${ }^{11}$, que hace del pensamiento fuerte (Denken) una débil (Meinen). Es decir, que todo deviene en doxa, que manifiesta una «resistencia a las totalidades» $^{12}$, en la cual se privilegia la discontinuidad del proceso histórico, con lo cual el par dialéctico continuo/discontinuo se rompe discursivamente $\mathrm{y}$, por tanto, la Historia (Geschichte) se torna discurso (Historie). Además, esta esquizo-fragmentación conlleva un repunte de lo particular sobre lo general. De ahí, que el autor posmoderno trate de evitar crear verdades de carácter universal. La posmodernidad se caracteriza por un discurso autorreferencial, la muerte del autor, la discontinuidad, el descentramiento del sujeto y, punto importante, la muerte de la utopía y, consecuentemente, del socialismo $^{13}$. La posmodernidad es la ideología de la globalización.

\section{Utopía y antiutopía}

Alrededor del concepto de utopía, se distingue entre dos tipos. Por un lado, las denominadas «realidades utópicas» que corresponden a aquello que aún no es, pero que puede llegar a ser; es decir, las realidades utópicas refieren a la posibilidad presente en la realidad. Las realidades utópicas son producto de la aplicación de las categorías de lo abstracto y lo concreto, en donde un cuerpo teórico (lo abstracto) somete al análisis lo concreto (el objeto de estudio) y, luego, se replantea lo abstracto inicial que fue afectado y transformado en su relación con lo concreto, para así acceder a una mejor comprensión

\footnotetext{
${ }^{10}$ Jacques Derrida, Lécriture et la différence (París: Éditions du Seuil, 1967) 107. Traducción de R. A. V.

${ }^{11}$ Jameson, 294.

12 Jameson, 321.

${ }^{13}$ Alvarado Vega, 77.
} 
(Verstehen) de la realidad. Por otro lado, está el concepto de «ilusiones utópicas» ${ }^{14}$, que remite a aquellas construcciones que se insertan en lo no posible; corresponden a lo que no puede $\operatorname{ser}^{15}$. Si las realidades utópicas tienen un arraigo en la materialidad del mundo, las utópicas son la expresión moral o intuitiva de una conciencia que muestra su descontento con la realidad que se vive, pero que no se visualiza materialmente, sino, al contrario, dentro de una visión idealista.

Históricamente, la utopía ha pasado de ser un discurso con un carácter epistemológico idealista, a ser una visión científica (Wissenschaftlich) de la realidad, cuya mejor expresión es la dialéctica negativa ${ }^{16}$ desarrollada por Hegel y Marx, y retomada posteriormente por la primera Escuela de Frankfurt ${ }^{17}$. Así, vamos desde las primeras utopías clásicas, por ejemplo La República de Platón, pasando por Utopia (1516) de Tomás Moro, quien bautiza este género en literatura, hasta el auge renacentista, cuando sobresalen La ciudad del sol (1602) de Campanella y New Atlantis (1624) de Francis Bacon ${ }^{18}$.

Hacia el siglo XIX, la utopía de corte moriano adquiere un rasgo científico dejando atrás el carácter antihistórico. La utopía, que empezó siendo un género literario y que planteaba fundamentalmente una serie de ciudades imaginarias que eran producto de una crítica

14 Esto es lo que Hinkelammert llama utopías estáticas, véase: Franz J. Hinkelammert, Crítica de la razón utópica (San José, Costa Rica: DEI, 2000) 258.

${ }^{15}$ Raúl Vidales, Utopía y liberación: el amanecer del indio (San José, Costa Rica: DEI, 1991) 25.

16 Confróntese para un acercamiento a la dialéctica: Roy Alfaro Vargas, «La sociología crítica de Henri Lefebvre», Revista de Ciencias Sociales III/IV, 113114 (2006): 97-104.

${ }^{17}$ Theodor W. Adorno, Dialéctica negativa (Madrid: Taurus Ediciones, 1975).

${ }^{18}$ Es preciso tener en mente que, con Bacon, se inaugura la denominada utopía tecnológica, que desemboca, en el siglo XX, en la distopía. Confróntese: Josecarlos Martínez García, «Historia de la Utopía: del Renacimiento a la Antigüedad», Espéculo. Revista de Estudios Literarios (2005); en línea; consultado 3 de mayo de 2006; disponible en: <http://www.ucm.es/info/especulo/numero30/l iutopic.html>. El concepto de distopía coincide con lo que denominaremos más adelante como antiutopía. 
moral de la sociedad en donde se ubicaba el escritor, pasa a ser crítica social, anclada en el análisis de las condiciones de existencia como un medio para plantear de manera antitética una sociedad organizada de modo diferente ${ }^{19}$. Adquiere un rasgo histórico que plantea una relación entre las categorías dialécticas de realidad y posibilidad, en donde el objeto ya no es construir un relato (Historie) sino asumir la Historia (Geschichte) como producto del sujeto histórico. Por tanto, entre las utopías literarias y la científica se produce una quiebra epistemológica, que conlleva la superación (Aufhebung) de la separación entre Ser y pensamiento que fundamenta el discurso utópico de características morianas.

Dentro de este contexto se desarrolla paralelamente la antiutopía. Separada de la visión planteada en las primeras utopías, en que se representa una sociedad mejor que la vivida por el escritor, plantea un futuro lleno de pesimismo y tragedia. Está la denominada distopía. La antiutopía se liga en ocasiones al desarrollo tecnológico; por ejemplo, en 1984 (1949) de George Orwell, el desarrollo tecnológico permite a una sociedad represiva obtener todo el control posible sobre el individuo, de tal manera que hasta los pensamientos pueden ser objeto de control. También, se ve en películas como Matrix (1999) en que el hombre es presa de una realidad virtual regida por una máquina, la cual lo convierte en algo así como una simple batería. Las antiutopías son una expresión de ilusión utópica, que contiene aquel elemento antihistórico que caracterizó las utopías renacentistas. Las antiutopías rompen su lazo con el humanismo renacentista y terminan siendo la expresión de cierta misantropía, que reduce al hombre a un simple juguete del destino. Esto supone un retroceso en relación con el desarrollo de la dialéctica negativa.

${ }^{19}$ Caroline Granier, «1c. Les 'utopies sociales' à la fin du dix-neuvième siècle». R.A. Forum; en línea, consultado 26 de junio de 2006; disponible en: <http://raforum.apinc.org/article.php3?id_article=2361>. 


\section{De la antiutopía en Cantos de las guerras preventivas}

El primer contacto con el carácter antiutópico de Cantos de las guerras preventivas lo tenemos con el epígrafe ${ }^{20}$. Este peritexto cumple dos funciones; la primera es la de comentario del título ${ }^{21}$, ya que justifica y esclarece el título de la novela, por cuanto nos ubica en un paisaje de guerra, teñido por la sangre y la putrefacción, lo cual semánticamente se relaciona con la noción de guerra del título. Además, el epígrafe remite a la función de comentario del texto, en tanto subraya indirectamente la significación del texto; es decir, el ambiente de guerra descrito por el epígrafe se termina relacionando estrechamente con la temática desarrollada en el texto. Cantos de las guerras preventivas desarrolla una trama marcada por un caos propio de una guerra guiada por la Mega Empresa Planetaria, mediante sus instrumentos políticos, especialmente por el Máximo Órgano (antigua ONU):

No te vamos a contar de armas ni de varones ilustres porque armas sí hay; pero varones ilustres ya no quedan.

Son tiempos de hombres sin gloria y dioses impávidos.

No hay héroes, ni monstruos dignos, sino cobardes que arrasan pueblos enteros sin moverse de sus casas.

El mundo todo cabe en la pantalla de un ordenador.

El destino de muchas generaciones cabe en un botón (13).

Así, el epígrafe, como primer elemento significante, plantea un topós que, en ningún sentido, corresponde con la visión de una

${ }^{20}$ «Y todo esto pasó con nosotros. /Nosotros lo vimos, /nosotros lo admiramos. /Con esta lamentosa y triste suerte /nos vimos angustiados. //En los caminos yacen los dardos rotos, /los cabellos están esparcidos. /Destechadas están las casas, /enrojecidos tienen sus muros. //Gusanos pululan por calles y plazas, /y en las paredes están salpicados los sesos. /Rojas están las aguas, están como teñidas /y cuando las bebimos, /fue como si bebiéramos agua de salitre. /Anales de Tlatelolco» (11).

${ }^{21}$ Esta noción y la de función de comentario del texto son de: Gérard Genette, Seuils (París: Éditions du Seuil, 1987) 145-6. 
sociedad mejor que aquella donde el escritor-narrador se sitúa ${ }^{22}$. No obstante, en el Preludio hallamos el elemento que textualmente ubica la novela como una utopía: «Año del Señor de 2034» (14). El texto es narrado en un espacio temporal situado en el futuro, en tanto visión pesimista dada desde la situación temporal del acto de escritura. Este factor temporal, unido a las funciones del epígrafe, implica una visión antiutópica, reforzada a lo largo del texto con otros elementos que serán analizados seguidamente.

Es importante, asimismo, rescatar el factor tecnológico. Al igual que en 1984, en esta obra de Contreras, existe un panoptismo, que permite el control social, manifiesto en la televisión y en el desarrollo satelital. Por ejemplo: «Un circuito cerrado de televisión ponderará noche y día hasta el más insignificante movimiento en kilómetros a la redonda» (16). El ser humano es objeto de un constante control, en donde su humanidad y su subjetividad histórica, yacen bajo el peso de una agencia histórica de tipo racionalreproductiva $^{23}$. También, es evidente el importante papel que desempeña el desarrollo tecnológico centrado en la fabricación de armamento, el cual es utilizado indiscriminadamente, produciendo el angustiante ambiente, con el cual el epígrafe nos puso inicialmente en contacto.

Por consiguiente, Cantos de las guerras preventivas plantea una fuerte relación intertextual con las utopías tecnológicas, en tanto el elemento tecnológico es fundamental en la representación del espacio bélico de esta novela; entonces, ya podemos llamar

${ }^{22}$ Esta característica estructural es compartida con Los Peor, de Contreras, en cuyo epígrafe también se hace un entronque con el registro utópico. Dice el epígrafe: «Así que no nos debe /parecer absurdo que /como en cada nación /hay algunos hombres /monstruosos, así /generalmente en todo /el linaje humano /haya algunas gentes y /naciones monstruosas. //San Agustín. La Ciudad de Dios» (San José: Farben, 1995) 12. Dentro del diégesis textual de Los Peor, este epígrafe termina siendo fundamental como programador de una lectura trágica y pesimista.

${ }^{23}$ Para acceder a una mejor comprensión de los conceptos de agencia histórica y de subjetividad histórica, ver Roy Alfaro Vargas, «Antropologías literarias: prolegómenos a la praxis textual», Praxis LVIV (2007): 11-12. 
definitivamente antiutópico a este texto. Su antiutopicidad toma una mejor caracterización de Cantos de las guerras preventivas con la incorporación de la circularidad temporal que se plantea en relación con el Plan Alternativo. Dentro del Plan, se pretende democratizar la violencia institucionalizada, o sea, la violencia de la guerra. Esto sería una especie de autogenocidio, en el cual se crearían las condiciones para regresar al origen: «Regresaríamos al principio para comenzar de cero, seríamos nómadas de nuevo, para que no quedara un palmo de la tierra desconocido para los pies que volverían sobre sus pasos de destruirlo todo» (26).

Esto sería la posibilidad ofrecida por el Plan Alternativo, que fue desechado. No obstante, dentro el Plan de las guerras preventivas (28), que fue llevado a cabo, el resultado fue similar en cuanto se retorna a un período marcado por la preeminencia de lo natural sobre lo social: «Se dice que la selva es espesa y que después de las costas del mundo está sembrado de ruinas. Son las ruinas del mundo ya cumplido, que se las ha tragado la selva» (151).

La humanidad ha retornado al génesis, cuando su filogenia era presa de la naturaleza. Realmente, el tiempo no existe, o existe únicamente como eterno retorno. Esta circularidad toma forma cuando se dice: «El proyecto tardaría una era geológica, diez mil años y uno» (27). 10001 es el número que representa la repetitividad, leído de izquierda a derecha o viceversa, el resultado es siempre el mismo. Es la identidad que se consume a sí misma, por cuanto la flecha del tiempo $^{24}$, que abarca pasado-presente-futuro, se funde en un ayer que se ve con culpa (correspondiente al contexto de escritura) y un presente (correspondiente al período de 2034) que no ofrece otra salida que repetir. $\mathrm{O}$ sea, la idea de un tiempo antitético queda borrada en la autista circularidad del tiempo antiutópico de Cantos de las guerras preventivas.

El futuro es asumido desde una visión trágica, que lejos de ser el espacio-tiempo de innovación, es el espacio de expiación de culpas.

${ }^{24}$ Paul Davies, «La flecha del tiempo», Investigación y ciencia 314 (2002) 8-13. 
El futuro es el símbolo de la desesperanza, del miedo y de la desconfianza $^{25}$ : «Es natural que nosotros (...) reaccionemos con desconfianza cada vez que alguien nos lanza una pregunta que apunte hacia el futuro. Muy por el contrario de cuando se nos pregunta por el pretérito» (182).

El rechazo del futuro marca una temporalidad cerrada, en la cual se va del presente al pasado (pretérito), éste último elevado a sitio de confianza. El pasado es el espacio de evasión neurótica, en cuanto es la representación del útero, de donde, en algún momento, se salió. Es el pretérito de alguna nostálgica edad dorada, de una sociedad que ya no es. Es interesante observar aquí que el texto maneja implícitamente la oposición campo-ciudad ${ }^{26}$, ya que hay un estado crítico que es producto del caos social, o sea, la guerra. En cambio, en el estado final la selva retorna, de alguna manera al hombre a un espacio natural, que por no social semeja ser más puro.

\section{Cantos de las guerras preventivas y la posmodernidad}

Salta a la vista la relación entre Cantos de las guerras preventivas y la posmodernidad, con relación al desprecio por la utopía que ambas comparten, de ahí la visión antiutópica del texto. Sin embargo, hay otros elementos textuales que apuntan a establecer de manera más precisa la relación texto-posmodernidad. Para analizarlos, es imprescindible definir el concepto de deseo: el deseo es carencia, deseamos lo que no poseemos; la satisfacción del deseo es la ausencia

${ }^{25}$ Este es un motivo común en la novelística de Contreras, en Los Peor podemos leer: «Él había venido a ser una pieza anónima más en el ajetreo urbano de cada día, sin importarle a nadie si un día se le veía por ahí y otro no y sin saber tampoco él mismo si seguiría en esa rutina toda la vida que le quedara por delante, fundamentalmente por no verse nunca afectado con la obsesión por el futuro», en: Fernando Contreras Castro, Los Peor, 32. Jerónimo Peor manifiesta una franca aversión hacia el futuro, en tanto metáfora del desprecio posmoderno a las concepciones que plantean «realidades utópicas».

${ }^{26}$ Esta oposición es característica del capitalismo, desde sus inicios. Confróntese: Karl Marx y Frederick Engels, The German Ideology (Moscow: Progress Publishers, 1976) 72 y ss. 
de carencia, su eliminación. La anulación de la carencia lo experimentamos como placer; así, el placer absoluto sería la eliminación de todas las carencias, o sea, la muerte, único estado biológico en donde no se experimenta carencia alguna. Por ende, placer y muerte equivalen.

El deseo, por otra parte, es constante; una vez alcanzada alguna satisfacción, reaparece el deseo, porque éste siempre es insatisfecho. Dentro de este contexto, Žižek expresa que el capitalismo es «el reino del discurso de la Histérica: este círculo vicioso de un deseo, cuya aparente satisfacción solo amplia el hueco de su satisfacción, es lo que define la histeria» ${ }^{27}$. Es decir, que el capitalismo, especialmente en su actual versión bursátil, es siempre un deseo cuyo objeto es el deseo mismo. El deseo de acumular es siempre proporcional a lo acumulado y nunca encuentra satisfacción, ya que, se alimenta de sí mismo; es pura circularidad. Aparte de lo expresado por Žižek, el deseo siempre es deseo libidinoso. Es deseo sexual, en cuanto instinto primario. Cantos de las guerras preventivas muestra signos de representación y expresión de la líbido posmoderna, en el pasaje referido, en el canto I, al funeral del último Gerente General de la Mega Empresa Planetaria: «Sus amantes serán disecadas vivas y dejadas a su disposición en una cámara contigua. /La cámara de la primera dama tendrá acceso privado» (18).

Esta imagen fúnebre en sentido psicoanalítico condensa y desplaza el deseo, en tanto insatisfecho, debido a que la imagen del gerente es la metáfora de la guerra (recordemos que la Mega Empresa Planetaria es quien administra la guerra) que en tanto poder se une al deseo sexual (en este caso machista) de una poligamia de hecho. El deseo se muestra aquí como posesión. Se posee poder y se poseen «varias hembras». Así, «la tumba faraónica (sería el lugar) desde donde él querría ejercer el poder por los tiempos de los tiempos» ((20); paréntesis míos). Es un deseo tan fuerte que va más allá del

${ }^{27}$ Slavoj Žižek, «Eastern Europes Republic Gilead», New Left Review, 183 (1990) 59-60. Traducción de R. A. V. 
placer absoluto, al romper las barreras de la muerte, por cuanto «Se dice que entonces, resucitará de entre los muertos» (18). Es como si hubiese alguna «Carencia Absoluta», algo al modo de un «Espíritu Absoluto», que existiese más allá de las representaciones particulares de la carencia.

Este deseo insatisfecho de acumulación se enmarca dentro de la relación de subordinación que se establece entre la Mega Empresa Planetaria («aquella figura plenipotenciaria»(20)) y las Empresas Subsidiarias $^{28}$, en tanto, en un esquema tremendamente hedonista, quien más deseo insatisfecho posee, domina. Esta dominación tiene como fin que los Socios Principales mantengan «un nivel de vida suntuoso a un costo insostenible»; por eso, «la guerra era inevitable porque quienes querían hacerla eran los Socios Principales, dueños de las armas de última generación» (23). Por lo tanto, el deseo insatisfecho de los Socios Principales con respecto a la suntuosidad a la que aspiran, engendra la guerra que crea nuevos carencias que deben ser, a su vez, satisfechas: la circularidad del deseo se hace patente.

Esta circularidad aglutina la trama textual; aglutina incluso la propuesta ideológica, porque tal propuesta, a pesar de la decadencia que muestra la humanidad al final del texto, ya que, no tiene futuro; se dirige a no satisfacer su necesidad de futuro y crea un estado de carencia absoluto, en tanto que no es móvil. Esta incapacidad del sujeto de plantearse el futuro no es más que el sinthome, que crea «el único soporte positivo (...) el único punto que da congruencia al sujeto» ${ }^{29}$. De ahí que el pretérito les ofrezca confianza, «mientras que

${ }^{28}$ Empresas Subsidiarias (E. S.) son eliminadas por la Mega Empresa Planetaria «para evitarle la bancarrota» (21)

${ }^{29}$ Slavoj Žižek, El sublime objeto de la ideología (Buenos Aires: Siglo XXI, 2003) 110. Es interesante recalcar que más allá de la posición posmoderna que niega y rechaza todo pensamiento de carácter universal, lo cierto es que su reticencia al futuro que espacio del deseo por satisfacer es un universal que los aglutina y reprime, como no podría hacerlo otro valor universal. La idea de la muerte de dios presente en Cantos de las guerras preventivas está ligada a aquella idea nietzscheana de la muerte de dios como muerte de los Sistemas filosóficos, que, al 
del incierto futuro sólo podemos esperar aniquilación» (182); por ende, «la dominación y la exclusión son deseadas» ${ }^{30}$.

La renuncia y el rechazo con respecto al futuro son totalmente claros en la siguiente cita: «aquella antigua creencia errónea en un destino para la humanidad; creencia absurda que, como especie, no nos llevó más que por el camino equivocado de asumirnos como el paso intermedio entre el animal y el ángel, cuando ni los ángeles existen, ni los animales deben aspirar a trascendencia alguna, al menos no los de nuestra ralea» (20-21).

Se renuncia al futuro como espacio-tiempo de proyección de lo humano y, en el mismo proceso, se reduce su humanidad a una animalidad bestial que Cantos de las guerras preventivas representa en la bestialidad de la guerra. Así, como contrato de lectura y en relación con lo anterior, el narrador-escritor igualmente nos ofrece una poética pesimista: «No escribo para esparcimiento de las generaciones futuras pues no vive el futuro en ningún corazón. Escribo porque es absurdo escribir» (44). El acto de escritura pierde toda funcionalidad social. Luego, el relato es una verborrea autista sin supuesta finalidad.

En este absurdo contexto quedan las (pseudo)críticas que el texto pretende esgrimir. Es evidente que el texto pretende una metaforizada crítica contra el gobierno estadounidense y contra su política de guerras preventivas, de las cuales han sido ya víctimas Afganistán e Irak: « ¡Tiempos difíciles de vaqueros imbéciles persiguiendo terroristas inexistentes!» (92) La referencia a los vaqueros y a los terroristas (que fue la excusa dada por Bush) muestra el contexto extratextual, ligado al proceso de escritura.

La puesta en duda de la justificación divina de la guerra, la irónica idea de que «La empresa privada produce libertad», la mención de los «despiadados horarios laborales» y la denuncia de la

estilo hegeliano o kantiano, pretendían explicar la totalidad (ver (120) y (122)); Federico Nietzsche, Así hablaba Zaratustra (México: Editores Mexicanos Unidos, 1992) 17.

30 Jean-François Lyotard, Economía libidinal (México: Fondo de Cultura Económica, 1990) 20. 
represión como el mecanismo preferido de la Mega Empresa Planetaria $(21,46,92,142)$; no tiene ningún valor dentro de la ideología pesimista y fatalista que se representa en Cantos de las guerras preventivas. La crítica se reduce a hacer un inventario de hechos y no pasa de ahí. Los hechos materiales que reproducen la sociedad, se separan de la lucha por el poder. La supuesta ausencia de finalidad de Cantos de las guerras preventivas (dada en el contrato de lectura) queda aquí contradicha, cuando el esquema posmoderno termina siendo una crítica que no pone nada en duda y mantiene un silencio, que no asume las causalidades, y, por ende, se brinda implícitamente una separación entre economía y política.

\section{Conclusión}

Cantos de las guerras preventivas es una novela que asume como fundamento ideológico la posmodernidad, la cual sigue fielmente en tanto paradigma ético y gnoseológico. Reproduce el rechazo a cualquier noción de verdad clásica, así como a cualquier valor moral universalizable y universalizante. Dentro de esta propuesta novelística, el tiempo deviene expresión de una temporalidad cerrada que niega cualquier desarrollo utópico, en tanto proyecto ligado al futuro. El tiempo es mutilado por la novela, al representarlo como una circularidad que juega entre dos puntos: presente y pasado. El futuro es el espacio de un deseo que quiere y que se teme; el futuro es tan solo la expresión de un doble vínculo, lo cual convierte al texto en una antiutopía.

La crítica que Cantos de las guerras preventivas pretende sostener es más una expresión de crítica petite bourgeoise, que no asume las causalidades (presentando los hechos pseudocriticados en el aire) $\mathrm{y}$, consecuentemente, no hay propuestas para un proyecto futuro. Por todo lo dicho, Cantos de las guerras preventivas se estructura como una antiutopía, en la cual el deseo insatisfecho funciona como elemento aglutinante del relato, en tanto manifestación cultural posmoderna. 